International Journal of Pure and Applied Mathematics

Volume 105 No. 1 2015, 1-6

ISSN: 1311-8080 (printed version); ISSN: 1314-3395 (on-line version)

url: http://www.ijpam.eu

doi: http://dx.doi.org/10.12732/ijpam.v105i1.1

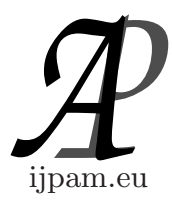

\title{
SUPER EDGE ANTI-MAGIC VERTEX LABELING AND SUPER EDGE ANTI-MAGIC TOTAL LABELING OF A CYCLE WITH ZIG-ZAG CHORDS
}

\author{
L. Girija ${ }^{1}$, A. Elumalai ${ }^{2}$ \\ ${ }^{1}$ Bharathiar University \\ Coimbatore, 641046, INDIA \\ ${ }^{2}$ Department of Mathematics \\ Valliammai Engineering College \\ Chennai, 603203, INDIA
}

\begin{abstract}
In this paper, we show that super edge anti-magic vertex labeling and super edge anti-magic total labeling of cycles by adding (n-3) zig-zag chords.

AMS Subject Classification: $05 \mathrm{C} 78$

Key Words: graph labeling, edge anti-magic vertex labeling, super edge antimagic vertex labeling, edge anti-magic total labeling, super edge antimagic total labeling,cycle with (n-3) zig-zag chords
\end{abstract}

\section{Introduction}

All graphs are finite, simple and undirected. The graph $\mathrm{G}$ has vertex-set $\mathrm{V}(\mathrm{G})$ and edge-set $\mathrm{E}(\mathrm{G})$. Unless otherwise noted, $|V(G)|=p$ and $|E(G)|=q$.

A labeling of a graph is any map that carries some set of graph elements to numbers (usually to the positive or non-negative integers). Magic labelings are one-to-one maps onto the appropriate set of consecutive integers starting from 1 , with some kind of "constant-sum" property.

Received: April 30, 2015

(C) 2015 Academic Publications, Ltd.

${ }^{\S}$ Correspondence author url: www.acadpubl.eu 
Simanjuntak, Miller and Bertault [8] defined an (a, d)-edge-antimagic vertex $((\mathrm{a}, \mathrm{d})-\mathrm{EAV})$ labeling for a graph $\mathrm{G}(\mathrm{V}, \mathrm{E})$ as an injective mapping $\mathrm{f}$ from $\mathrm{V}$ onto the set $\{1,2, \cdots, n\}$ with the property that the edge-weights $\{w(x y): w(x y)=$ $f(x)+f(y), x y \in E\}$, form an arithmetic sequence with the first term a and difference $\mathrm{d}$, where $a>0$ and $d \geq 0$ are two fixed integers. An (a,d)-EAV labeling is called super (a,d)-edge antimagic vertex ((a, d)-SEAV) labeling if $f(v)=\{1,2, \cdots, n\}$.

Acharya and Hegde [1] (see also [6]) introduced the concept of a strongly (a, d)-indexable labeling which is equivalent to (a, d)-EAV labeling. The relationship between the sequential graphs and the graphs having an (a, d)-EAV labeling is shown in [3].

An (a, d)-edge antimagic total ((a, d)-EAT) labeling is a bijection $\mathrm{f}$ from $V \cup E$ onto $\{1,2, \cdots, v+e\}$ with the property that the sums of the label on the edges and the labels of their end points form an arithmetic sequence starting from a and having a common difference $\mathrm{d}$. This labeling is a natural extension of the notion of edge magic labeling which was originally introduced by Kotzig and Rosa in [7], where edge-magic labeling is called magic valuation. Relationships between (a, d)-EAT labeling and other labelings, namely, (a, d)-EAV labeling are presented in $[2]$.

An (a, d)-EAT labeling is called super (a, d)-edge antimagic total ((a, d)SEAT) labeling if $f(V)=1,2, \cdots, n$. This labeling is a natural extension of the notion of a super edge-magic labeling defined by Enomoto et al. in [4]. A graph that has an (a, d)-EAV ((a, d)-EAT or (a, d)-SEAT) labeling is called an (a, d)-EAV ((a, d)-EAT or (a, d)-SEAT) graph. J.A. MacDougall and W.D. Wallis conjecture in [9] that every cycle with a chord is strong edge magic labeling. Also M. Baca and M. Murugan conjecture in [10] that every cycle with a chord is super edge-antimagic labelling.

A cycle with (n-3) chords is a graph obtained from a cycle $C_{n}(n \geq 4)$ by adding (n-3) zig-zag chords to the non-consecutive vertices of the cycle, that is between each pair of non adjacent vertices $v_{i} v_{(n-i+2)}$, for $2 \leq i \leq \frac{n}{2}$ and $v_{i} v_{(n-i+3)}$, for $3 \leq i \leq \frac{n}{2}$ for even cycles and $v_{i} v_{(n-i+2)}$, for $2 \leq i \leq \frac{n-1}{2}$ and $v_{i} v_{(n-i+3)}$, for $3 \leq i \leq \frac{n+1}{2}$ for odd cycles.

\section{Main Results}

Theorem 1. A cycle $C_{n}$ for $n \geq 4$ with (n-3) zigzag chords has a (3,1)super edge anti-magic vertex labeling.

Proof. Let $C_{n}$ be a cycle on $\mathrm{n}$ vertices. We denote the vertices of $C_{n}$ as 
$v_{1}, v_{2}, v_{3}, \cdots, v_{n}$ in the clockwise direction and denote the edges of $C_{n}$ with (n-3) zigzag chords as $e_{1}, e_{2}, e_{3}, \cdots, e_{(2 n-3)}$ such that $e_{i}=v_{i} v_{(i+1)}$ for $1 \leq i \leq(n-1)$, $e_{n}=v_{n} v_{1}$ and for chords,

when $n$ is even

$$
\begin{aligned}
e_{(n+i-1)} & =v_{i} v_{(n-i+2)}, 2 \leq i \leq \frac{n}{2} \\
e_{\left.\frac{(3 n+2 i-6}{2}\right)} & =v_{i} v_{(n-i+3)}, \quad 3 \leq i \leq \frac{n}{2}
\end{aligned}
$$

when $\mathrm{n}$ is odd

$$
\begin{gathered}
e_{(n+i-1)}=v_{i} v_{(n-i+2)}, 2 \leq i \leq \frac{n-2}{2} \\
e_{\left.\frac{(3 n+2 i-5}{2}\right)}=v_{i} v_{n-i+3}, 3 \leq i \leq \frac{n+1}{2}
\end{gathered}
$$

The labeling for the vertices of $C_{n}$ are given as follows. Define

$$
\begin{aligned}
f\left(v_{1}\right) & =2 n-2 \\
f\left(v_{2}\right) & =2 n-1 \\
f\left(v_{i}\right) & =f\left(v_{i-1}\right)+2,3 \leq i \leq \frac{n+2}{2}, \text { if neven } \\
f\left(v_{i}\right) & =f\left(v_{i-1}\right)-1, i=\frac{n+4}{2}, \text { if neven } \\
f\left(v_{i}\right) & =f\left(v_{i-1}\right)-2, \frac{n+6}{2} \leq i \leq n, \text { if n even } \\
f\left(v_{i}\right) & =f\left(v_{i-1}\right)+2,3 \leq i \leq \frac{n+1}{2}, \text { if } n \text { odd } \\
f\left(v_{i}\right) & =f\left(v_{i-1}\right)+1, i=\frac{n+3}{2}, \text { if nodd } \\
f\left(v_{i}\right) & =f\left(v_{i-1}\right)-2, \frac{n+5}{2} \leq i \leq n, \text { if } n \text { odd }
\end{aligned}
$$

From the above definition it is observed that the vertices of $C_{n}$ are labeled from 1 to $\mathrm{n}$ and are distinct. Now the edge-weights can be labelled as,

$$
\begin{aligned}
f\left(e_{i}\right) & =f\left(v_{i}\right)+f\left(v_{i+1}\right), 1 \leq i \leq n-1 \\
f\left(e_{n}\right) & =f\left(v_{n}\right)+f\left(v_{1}\right)
\end{aligned}
$$

when $\mathrm{n}$ is even, the edge labeling of chords are

$$
f\left(e_{(n+i-1)}\right)=f\left(v_{i}\right)+f\left(v_{n-i+2}\right), 2 \leq i \leq \frac{n}{2}
$$




$$
f\left(e_{\frac{3 n+2 i-6}{2}}\right)=f\left(v_{i}\right)+f\left(v_{n-i+3}\right), 3 \leq i \leq \frac{n}{2}
$$

when $\mathrm{n}$ is odd, the edge labeling of chords are,

$$
\begin{gathered}
f\left(e_{n+i-1}\right)=f\left(v_{i}\right)+f\left(v_{n-i+2}\right), 2 \leq i \leq \frac{n-1}{2} \\
f\left(e_{\frac{3 n+2 i-7}{2}}\right)=f\left(v_{i}\right)+f\left(v_{n-i+3}\right), 3 \leq i \leq \frac{n+1}{2}
\end{gathered}
$$

Hence the cycle $C_{n}$ with (n-3) zigzag chords has a $(3,1)$-super edge anti-magic vertex labeling.

Theorem 2. A cycle $C_{n}$ for $n \geq 4$ with (n-3) zigzag chords has a $(n+4,2)$ super edge anti-magic total labelling.

Proof. Let $C_{n}$ be a cycle on $\mathrm{n}$ vertices. We denote the vertices of $C_{n}$ as $v_{1}, v_{2}, v_{3}, \cdots, v_{n}$ in the clockwise direction and denote the edges of $C_{n}$ with n-3 zigzag chords as $e_{1}, e_{2}, e_{3}, \cdots, e_{2 n-3}$ such that $e_{i}=v_{i} v_{(i+1)}$ for $1 \leq i \leq n-1$, $e_{n}=v_{n} v_{1}$ and for chords,

when $\mathrm{n}$ is even

$$
\begin{aligned}
& e_{(n+i-1)}=v_{i} v_{(n-i+2)}, 2 \leq i \leq \frac{n}{2} \\
& e_{\frac{3 n+2 i-6}{2}}=v_{i} v_{(n-i+3)}, 3 \leq i \leq \frac{n}{2}
\end{aligned}
$$

when $\mathrm{n}$ is odd

$$
\begin{aligned}
& e_{(n+i-1)}=v_{i} v_{(n-i+2)}, 2 \leq i \leq \frac{n-1}{2} \\
& e_{\frac{3 n+2 i-7}{2}}=v_{i} v_{n-i+3}, 3 \leq i \leq \frac{n+1}{2}
\end{aligned}
$$

The labeling for the vertices of $C_{n}$ are given as follows.Define

$$
\begin{aligned}
f\left(v_{1}\right) & =2 n-2 \\
f\left(v_{2}\right) & =2 n-1 \\
f\left(v_{i}\right) & =f\left(v_{i-1}\right)+2,3 \leq i \leq \frac{n+2}{2} \\
f\left(v_{i}\right) & =f\left(v_{i-1}\right)-1, i=\frac{n+4}{2}, \text { if n even } \\
f\left(v_{i}\right) & =f\left(v_{i-1}\right)-2, \frac{n+6}{2} \leq i \leq n
\end{aligned}
$$




$$
\begin{aligned}
& f\left(v_{i}\right)=f\left(v_{i-1}\right)+2,3 \leq i \leq \frac{n+1}{2} \\
& f\left(v_{i}\right)=f\left(v_{i-1}\right)+1, i=\frac{n+3}{2}, \text { if nodd } \\
& f\left(v_{i}\right)=f\left(v_{i-1}\right)-2, \frac{n+5}{2} \leq i \leq n
\end{aligned}
$$

From the above definition it is observed that the vertices of $C_{n}$ are labeled from 1 to $\mathrm{n}$ and are distinct.

Now the edge-weights can be labelled as,

$$
\begin{aligned}
f\left(e_{i}\right) & =f\left(v_{i}\right)+f\left(v_{i+1}\right)+(n-2), 1 \leq i \leq n-1 \\
f\left(e_{n}\right) & =f\left(v_{n}\right)+f\left(v_{1}\right)+(n-2)
\end{aligned}
$$

when $\mathrm{n}$ is even, the edge labeling of chords are,

$$
\begin{aligned}
& f\left(e_{n+(i-1)}\right)=f\left(v_{i}\right)+f\left(v_{n-i+2}\right)+(n-2), 2 \leq i \leq \frac{n}{2} \\
& f\left(e_{\frac{3 n+2 i-6}{2}}\right)=f\left(v_{i}\right)+f\left(v_{n-i+3}\right)+(n-2), 3 \leq i \leq \frac{n}{2}
\end{aligned}
$$

when $\mathrm{n}$ is odd, the edge labeling of chords are,

$$
\begin{aligned}
f\left(e_{n+i-1}\right) & =f\left(v_{i}\right)+f\left(v_{n-i+2}\right)+(n-2), 2 \leq i \leq \frac{n-1}{2} \\
f\left(e_{\frac{3 n+2 i-7}{2}}\right) & =f\left(v_{i}\right)+f\left(v_{n-i+3}\right)+(n-2), 3 \leq i \leq \frac{n+1}{2}
\end{aligned}
$$

Hence the cycle $C_{n}$ with (n-3) zigzag chords has a $(\mathrm{n}+4,2)$-super edge anti-magic total labeling.

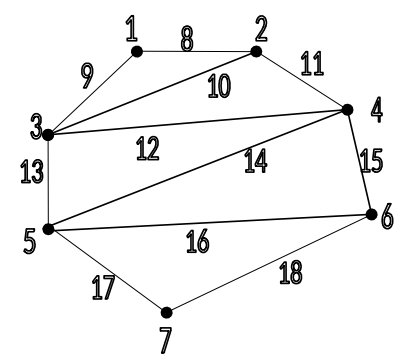

Figure 1: (11,2)-Super edge anti-magic total labeling of $C_{7}$ 
L. Girija, A. Elumalai

\section{References}

[1] B.D. Acharya and S.M. Hegde, Strongly indexable graphs, Discrete Math. 93 (1991), 275-299.

[2] M. Baca, Y. Lin, M. Miller and R. Simanjuntak, New constructions of magic and antimagic graph labelings, Utilitas Math. 60 (2001), 229-239.

[3] M. Baca andM.Z. Youssef, Further results on antimagic graph labelings, Austral.J. Combin. 38 (2007), 163-172.

[4] H. Enomoto, A.S. Llado, T. Nakamigawa and G. Ringel, Super edge-magic graphs, SUT J. Math. 34 (1998), 105-109.

[5] Gallian, A Dynamic survey of graph labeling, Electronic J. Combinatorics, Dec 29 (2014).

[6] S.M. Hegde, On indexable graphs, J. Combinatorics, Information and System Sciences 17 (1992), 316-331.

[7] A.Kotzig and A. Rosa, Magic valuations of finite graphs, Canad. Math. Bull.13 (1970), 451-461.

[8] R. Simanjuntak, M. Miller and F. Bertault, Two new (a, d)-antimagic graph labelings, Proceedings of the Eleventh Australasian Workshop on Combinatorial Algorithms(2000), 179-189.

[9] MacDougall and W.D. Wallis ,Strong edge-magic labelling of a cycle with a chord, Australasian journal of combinatorics Volume 28 (2003), Pages 245-255.

[10] M.Baca and M. Murugan, Super edge-antimagic labelling of a cycle with a chord, Australasian Journal of Combinatorics Volume 35(2006), Pages 253-261. 